two groups. In covariance analysis the qEEG parameter differences between the index group and controls were partly explained by the neurotic traits and emotional tension characteristic of the children with spelling difficulties. (Byring RF et al. EEG in children with spelling disabilities. Electroenceph clin Neurophysiol Oct $1991 ;$ 79:247-255).

COMMENT. Poor rhythmicity and low voltage of the background rhythm has been found in the EEG of children with learning disabilities, and visual EEG analysis has shown a large variety of EEG abnormalities associated with dyslexia (Hughes JR. In: Benton AL and Pearl D (Eds), Dyslexia - An Appraisal of Current Knowledge, Oxford University Press, New York. 1978:205-249. The present authors stress that psychopathology may be a confounding factor in the interpretation of EEG abnormalities in association with spelling disabilities and dyslexia.

\title{
ETIOLOGY OF ATTENTION DEFICIT DISORDERS
}

Familial-genetic factors in the etiology of attention deficit disorder $(\mathrm{ADDH})$ were studied in 145 children who met the DSM-III criteria at the Neuropediatrics Unit, Shaare Zedek Medical Center, Jerusalem, Israel. Boys outnumbered girls by $3: 1$. $30 \%$ of ADDH children had siblings with LD, compared to $6.7 \%$ in 30 normal children. $34 \%$ of ADDH children were of North African descent which comprised only $12 \%$ of the population in Jerusalem. ADDH was correlated with delayed language development and intrauterine growth retardation. No correlation was found between ADDH and numerous pre- and peri-natal factors, IQ, parental age, years of education, profession, and language spoken at home (Gross-Tsur V et al. Attention deficit disorder: association with familial-genetic factors. Ped Neurol July/Aug 1991; $\underline{7}: 258-261$ ).

COMMENT. A familial-genetic factor has been implicated in the etiology of ADHD in previous studies and the present report supports this finding. The familial-genetic factor was expressed by the male preponderance, the increased frequency of learning disabilities in siblings and an ethnic propensity. A delay in language development should alert the pediatrician to the possible development of ADDH and the need for early intervention programs. The benefits of early educational programs for parents concerning methylphenidate in the treatment of ADHD are demonstrated in a report from The Children's Hospital of Michigan, Detroit (Liu C et al. Social acceptability of methylphenidate and behavior modification for treating attention deficit

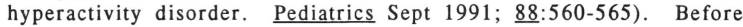
educational intervention families rated behavior modification as the most acceptable and methylphenidate as the least acceptable method of management. After 3-1/2 months experience with interventions for their children there was a significant increase in acceptability of methylphenidate related to the parental education about ADHD. 